\title{
A morphological study of retromolar foramen and retromolar canal of modern and medieval population
}

\author{
I. Komarnitki1, 2, H. Mańkowska-Pliszka', P. Roszkiewicz³ , A. Chloupek² \\ ${ }^{1}$ Department of Descriptive and Clinical Anatomy, Medical University of Warsaw, Poland \\ ${ }^{2}$ Clinical Department of Craniomaxillofacial Surgery, Military Institute of Medicine, Warsaw, Poland \\ ${ }^{3}$ Dental and Laser Medicine Centre, Laski, Poland
}

[Received: 30 September 2019; Accepted: 31 October 2019]

\begin{abstract}
Background: Retromolar foramen (RMF) is small external orifice of the retromolar canal (RMC), located in the retromolar region of the mandible. Knowledge about the location of the RMF and the route of the RMC within the mandible is significant for clinical practice due to a high risk of injury during oral and craniomaxillofacial surgery. Materials and methods: In this study, the authors analysed 100 cone-beam computed tomography (CBCT) scans of the modern people's retromolar region and 26 scans of samples from the medieval population. Additionally, 74 retromolar regions of the medieval people were examined macroscopically.

Results: The statistical analysis showed a correlation between the frequency of $R M C$ occurrence and bone thickness on the medial surface of the RMC. Also it was proven that the results of the RMF identification based on macroscopic examination of the bone may be falsely negative or positive and it is caused by destruction caused by resting in soil.

Conclusions: Thus, CBCT is the best tool for RMF and RMC identification. (Folia Morphol 2020; 79, 3: 580-587)
\end{abstract}

Key words: retromolar foramen, retromolar canal, cone-beam computed tomography

\section{INTRODUCTION}

The retromolar canal (RMC) is a rare extension of the mandibular canal. This small canal begins in the frontal part of the mandibular canal and ends with the retromolar foramen (RMF) on the upper surface of the alveolar part of the mandible in the retromolar region [11]. RMC includes the retromolar branch of the inferior alveolar artery [5, 24]. Deeper understanding of the retromolar region anatomy, location of the RMF and route of the RMC allows to precisely conduct many mandibular surgeries such as bone harvesting for autogenous bone graft, extraction of third molars and prevents complications caused by bleeding [5].
Among many studies focusing on anatomical variations of the mandibular foramen and the topography of the mandibular canal $[6,8,19,21,22]$, only few describe the RMC (Table 1). A significant problem in the literature is the classification and nomenclature of RMC. Some authors believe that RMC is one of many anatomical forms of double or triple mandibular canal, which begins in the main canal and ends in the retromolar region $[15,16]$. Other authors suggest that RMC is a different structure, underlining its clinical significance [11, 20,25].

Kuribayashi et al. [15] allocate RMC to type IV double mandibular canal with a frequency of $1.66 \%$

Address for correspondence: Dr. I. Komarnitki, Department of Descriptive and Clinical Anatomy, Medical University of Warsaw, ul. Chałubińskiego 5, 02-004 Warszawa, Poland, e-mail: anatomy@onet.eu 
Table 1. Retromolar canal frequency on cone-beam computed tomography (CBCT) scans

\begin{tabular}{lccccc}
\hline Publication & N/mandible side & Frequency (\%) & $\begin{array}{c}\text { N/number } \\
\text { of patients }\end{array}$ & Frequency (\%) & Type of examination \\
\hline Nortje et al. (1977) [20] & $242 / 7224$ & 3.3 & $121 / 3612$ & 3.3 & Panoramic \\
Langlais et al. (1985) [16] & $54 / 12000$ & 0.45 & $22 / 6000$ & 0.36 & Panoramic \\
Bilecenoglu and Turner (2006) [5] & $12 / 80$ & $15 \%$ & 40 & 30 & Macroscopic on bone material \\
Kuribayashi et al. (2010) [15] & $5 / 301$ & 1.66 & $5 / 252$ & 1.98 & CT \\
von Arx et al. (2011) [25] & $31 / 121$ & 25.6 & 100 & 31 & CBCT \\
Kawai et al. (2012) [12] & $34 / 90$ & 37 & $24 / 46$ & 52 & Macroscopic on preserved specimen \\
Han and Hwang (2014) [11] & $38 / 892$ & 4,26 & $38 / 446$ & 8.5 & CBCT \\
Kikuta et al. (2018) [14] & $15 / 100$ & 15 & $13 / 50$ & 26 & CBCT \\
\hline
\end{tabular}

(5 for every 301 mandibular sides) in their classification.

Langlais et al. [16] classify this type of branches as type 1 in their classification of additional mandibular canals and give the frequency of $0.36 \%$ (22 for every 6000 patients).

Nortje et al. [20] include RMC in type 2 (out of 16) of double mandibular canal in their classification, based on the analysis of the panoramic radiographs, with a frequency of 3.3\% (121 for every 3612 patients).

Due to the lack of a comparative work of RMC and RMF based on the archaeological material, our research is focused on the comparative analysis of modern population and material from the middle ages. Additionally, we evaluated carefully the RMF and RMC topography in terms of surrounding structures in the retromolar region, which is highly significant for prevention of surgical complications.

\section{MATERIALS AND METHODS}

The study was based on two groups, including modern population and medieval population.

Examination of the modern population was conducted using cone-beam computed tomography (CBCT) scans, which were obtained using Toshiba PCH6500. The material was taken from the archives of the Clinical Department of Craniomaxillofacial Surgery, Military Institute of Medicine in Warsaw, Poland. The analysis of scans was conducted using Ez3D Plus software.

The analysis of the modern material consisted of 100 measurements of the retromolar regions (37 men and 63 women). Mean age of the patients was 47.91 years (min. 16, max. 87). Following parameters were measured: morphometric diameter, length and direction of RMC in sagittal and frontal planes. Other parameters included the distance from RMF to the distal surface of the third and second molars as well as to the medial and lateral surfaces of the alveolar part of the mandible. Additional measurements included width and height of the mandibular canal in the retromolar region in different planes as well as the distance from the mandibular canal to the medial and lateral surfaces and to the upper edge of the alveolar part of the mandible (Fig. 1B).

The examination of the medieval population was based on the analysis of the osteological material from the collections of the Department of Descriptive and Clinical Anatomy, Medical University of Warsaw. The medieval samples were divided into two subgroups: i) material examined using morphometric techniques, ii) material examined using both morphometric techniques and $C B C T$ imaging. CBCT examination was conducted using New Tom $5 \mathrm{G}$ apparatus. The analysis of planes was conducted using NNT 3D Imaging software (Fig. 1B). Mandibles were randomly selected. They came from 50 people from the following age categories: juvenis, adultus, maturus and senilis of both genders. The age and gender was determined using general methods of anthropological analysis and description $[2,4]$. Mandibles were measured according to the principles of so-called Martin's techniques [18] using electronic spreading calliper as shown in Figure $1 \mathrm{~A}$. The first subgroup consisted of 74 individuals (49 men and 25 women), with a mean age of 40.05 years (min. 17, max. 60). The second subgroup consisted of 26 individuals ( 20 men and 6 women), with a mean age of 48 years ( $\min .20, \max .60$ ).

\section{Statistical analysis}

To address the research questions, the statistical analysis was conducted, using TIBCO Statistica 13.3 software. To describe the examined population, the following methods were used: Shapiro-Wilk test for 


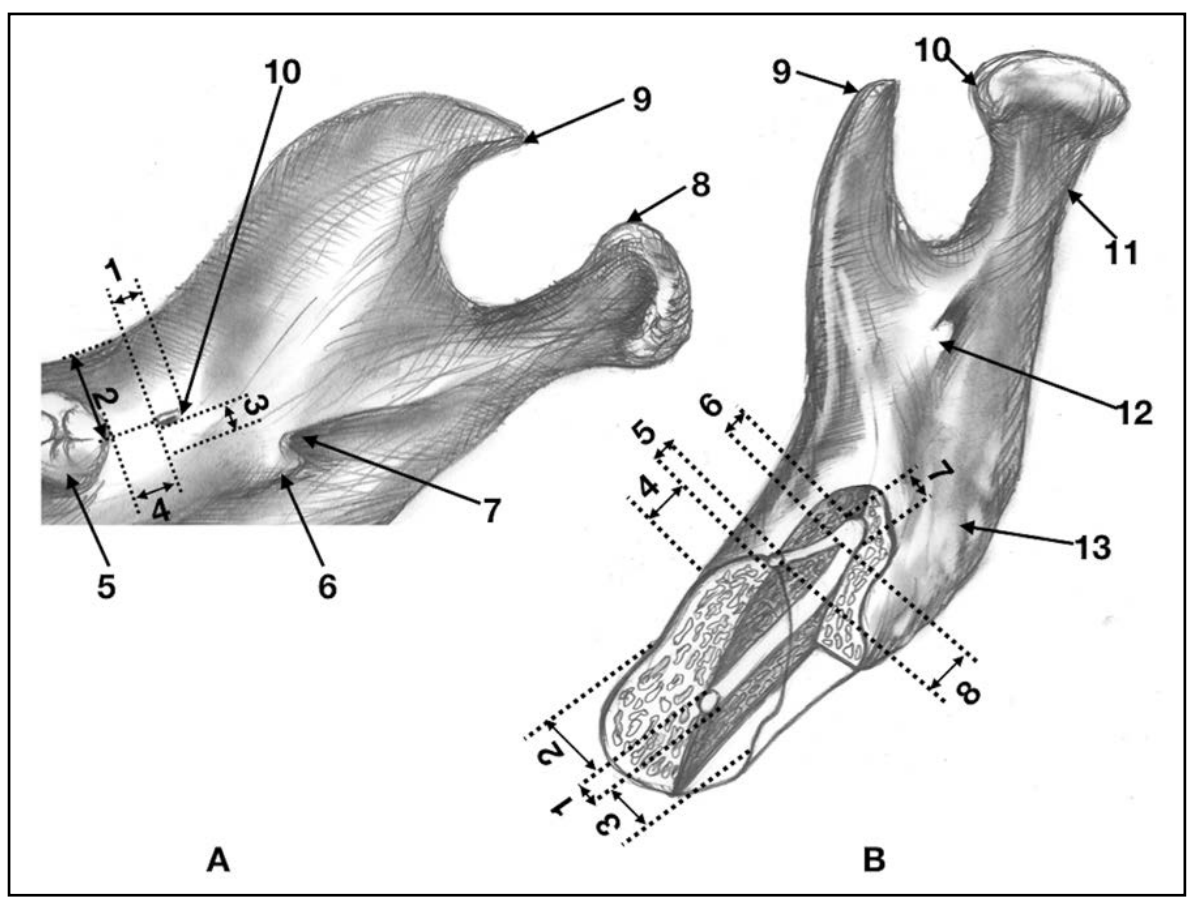

Figure 1. Main morphometric measurements (drawing by the author); A. Based on gross evaluation; 1 - retromolar foramen (RMF) diameter; 2 - distance from RMF to the lateral surface of the body of the mandible; 3 - distance from RMF to the medial surface of the body of the mandible; 4 - distance from RMF to the distal surface of the last tooth; 5 - right lower molar; 6 - lingula of the mandible; 7 - mandibular foramen; 8 - head of the mandible; 9 - coronoid process; B. Based on cone-beam computed tomography; 1 - mandibular canal diameter; 2 - distance from the mandibular canal to the lateral surface of the body of the mandible; 3 - distance from the mandibular canal to the medial surface of the body of the mandible; 4 - distance from RMF to the lateral surface of the body of the mandible; 5 - RMF diameter; 6 - initial retromolar canal (RMC) diameter; 7 - mandibular canal diameter at the level of RMC origin; 8 - RMC length; 9 - coronoid process; 10 - head of the mandible; 11 - neck of the mandible; 12 - lingula; 13 - pterygoid tuberosity.

Table 2. General descriptive statistics of the quantitative variables

\begin{tabular}{lccccccccc}
\hline & M & Me & Min. & Max. & SD & Sk. & Kurt. & SW & P \\
\hline Age & 44.03 & 45.00 & 16.00 & 87.00 & 16.82 & 0.12 & -0.98 & 0.955 & $<0.001$ \\
Height of the mandibular canal in the sagittal plane & 3.00 & 3.00 & 1.40 & 4.70 & 0.70 & 0.25 & -0.16 & 0.987 & 0.286 \\
Canal-mandibular edge distance in the sagittal plane & 9.45 & 9.50 & 2.50 & 20.10 & 2.61 & 0.39 & 1.94 & 0.974 & 0.015 \\
Mandibular canal width in the frontal plane & 2.92 & 2.80 & 1.70 & 4.60 & 0.56 & 0.44 & 0.05 & 0.981 & 0.076 \\
Canal-mandibular edge distance in the frontal plane & 11.34 & 11.10 & 1.10 & 24.20 & 3.89 & 0.27 & 1.15 & 0.980 & 0.063 \\
Canal-facial surface distance in the frontal plane & 4.01 & 3.80 & 1.30 & 8.40 & 1.41 & 0.79 & 0.60 & 0.957 & 0.001 \\
Canal-medial surface distance in the frontal plane & 2.88 & 2.70 & 0.50 & 8.70 & 1.48 & 0.99 & 1.69 & 0.941 & $<0.001$ \\
\hline
\end{tabular}

M — mean value; Me — median; Min and Max. — minimum and maximum of distribution; SD — standard deviation; Sk — skewness; Kurt. — kurtosis; SW — Shapiro-Wilk test result; $\mathrm{P}$ - significance

evaluation of the random variable distribution, Student's t-test for independent samples, Fisher test and McNemar test of correlation analysis using Pearson's $r$ coefficient and analysis of logistic regression correlation. Statistical significance level was set for $\alpha=0.05$.

\section{RESULTS}

The first stage of our research included basic descriptive statistics of quantitative variables and Shapiro-Wilk test for normality of distribution of those vari- ables. It showed that the distribution of the vertical dimension of the mandibular canal in the sagittal plane, width of the mandibular canal in the frontal plane, distance between mandibular canal and the edge of the mandible in the frontal plane did not differ significantly from the normal distribution, which proves that the studied group was representative (Table 2).

The next stage was a comparison of the modern material with the archaeological material for selected mandibular dimensions measured on CBCT. 
Table 3. Comparison of different anatomical mandibular distances in modern and archaeological material measured on cone-beam computed tomography

\begin{tabular}{|c|c|c|c|c|c|c|c|c|c|}
\hline & \multicolumn{2}{|c|}{$\begin{array}{c}\text { Archaeological } \\
\text { material }(n=26)\end{array}$} & \multicolumn{2}{|c|}{$\begin{array}{l}\text { Modern material } \\
\quad(\mathrm{n}=\mathbf{1 0 0})\end{array}$} & \multirow[b]{2}{*}{$\mathbf{t}$} & \multirow[b]{2}{*}{$\mathbf{P}$} & \multicolumn{2}{|c|}{$95 \% \mathrm{Cl}$} & \multirow[b]{2}{*}{ d Cohen } \\
\hline & M & SD & M & SD & & & LL & UL & \\
\hline Mandibular canal height in sagittal plane & 2.80 & 0.47 & 3.05 & 0.74 & -2.14 & 0.036 & -0.49 & -0.02 & 0.32 \\
\hline Canal-mandibular edge distance in sagittal plane & 9.64 & 1.99 & 9.40 & 2.75 & 0.41 & 0.681 & -0.72 & 1.19 & 0.14 \\
\hline Mandibular canal width in frontal plane & 2.66 & 0.52 & 2.98 & 0.55 & -2.68 & 0.008 & -0.56 & -0.09 & 0.46 \\
\hline Canal-mandibular edge distance in frontal plane & 10.54 & 2.98 & 11.55 & 4.08 & -1.19 & 0.237 & -2.45 & 0.41 & 0.45 \\
\hline Canal-lateral surface distance in frontal plane & 3.50 & 1.42 & 4.15 & 1.39 & -2.10 & 0.038 & -1.27 & -0.01 & 0.52 \\
\hline Canal-medial surface distance in frontal plane & 3.06 & 1.49 & 2.84 & 1.48 & 0.68 & 0.495 & -0.44 & 0.89 & 0.18 \\
\hline
\end{tabular}

$\mathrm{n}$ - number of observations; $\mathrm{M}$ - mean value; $\mathrm{SD}$ — standard deviation; $\mathrm{t}$ - Student's t-test; $\mathrm{P}$ - statistical significance; $95 \% \mathrm{Cl}$ - confidence interval; $\mathrm{LL}$ and $\mathrm{UL}$ - lower and upper limit of the confidence interval

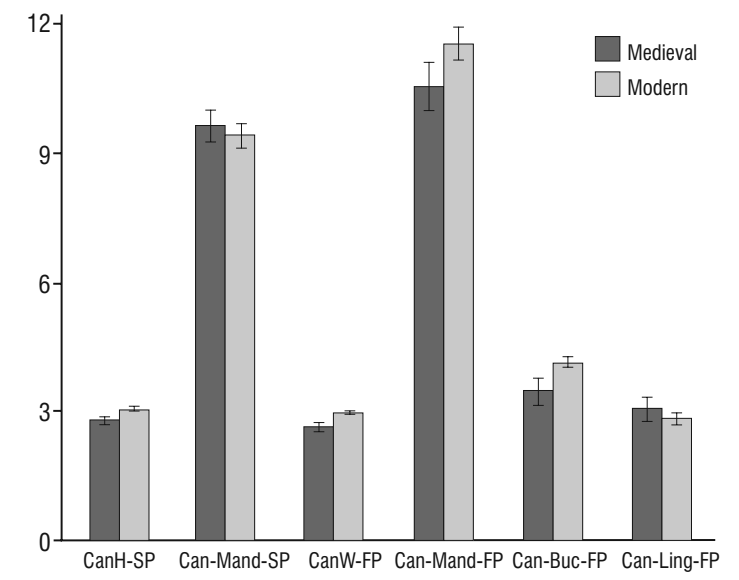

Figure 2. Comparison of current and archaeological material with regard to selected anatomical parameters measured on cone-beam computed tomography; CanH-PS — canal height in the sagittal plane; Can-Mand-SP — canal-mandibular edge distance in the sagittal plane; CanW-FP — canal width in the frontal plane; Can-Mand-FP — canal-mandibular edge distance in the frontal plane; Can-Buc-FP - canal-lateral surface distance in the frontal plane; Can-Ling-FP — canal-medial surface distance in the frontal plane.

It turned out that the modern material is characterised by significantly greater vertical width of the mandibular canal in the frontal plane, significantly greater vertical width of the mandibular canal in the sagittal plane, significantly greater distance between the wall of the mandibular canal and fascial surface of the mandible. The strength of the observed correlations, assessed by Cohen's d coefficient, was medium and large for the last two correlations, respectively. Other anatomical dimensions are not characterised by statistically significant differences. Thus there are no statistically significant quantitative differences, described by measuring distances, between modern and medieval populations (Table 3, Fig. 2).
We conducted the comparison of RMF occurrence in modern and archaeological material (on macroscopic examination) using Fisher's test. The result was statistically significant with $p$-value $<0.001$. It means that the additional branch of the mandibular canal occurred significantly more frequently in the archaeological material (measured using macroscopic techniques) $54.05 \%$ compared to modern humans $-10.00 \%$. The result for the medieval mandibles may be overestimated due to taphonomical changes in bones resulting from soil deposition (grave pits). Comparative analysis of additional mandibular branch frequency between modern material $10.00 \%$ and archaeological (measured using CBCT) $3.85 \%$ showed that the difference between both populations is not statistically significant in this case: $p=0.456$ (Fisher's exact test). It indicates that potential post mortem changes of the medieval mandibles do not affect the overall result of the analysis.

In the next stage, we tried to answer the question whether there are any differences between parameters of the mandibular canal branching of modern (measured on CT examination) and medieval (measured by external inspection) populations. For this we conducted Student's t-test for independent samples.

It turned out that the distance between RMC and facial surface of the mandible was significantly greater in the archaeological material rather than in the modern one. The strength of the dependence, measured by Cohen's $d$ coefficient was very high.

No statistically significant differences between archaeological and modern material in other parameters were observed. In the archaeological material, distributions of other variables were not significantly asymmetric. Because the only statistically significant difference between both populations was in the dis- 


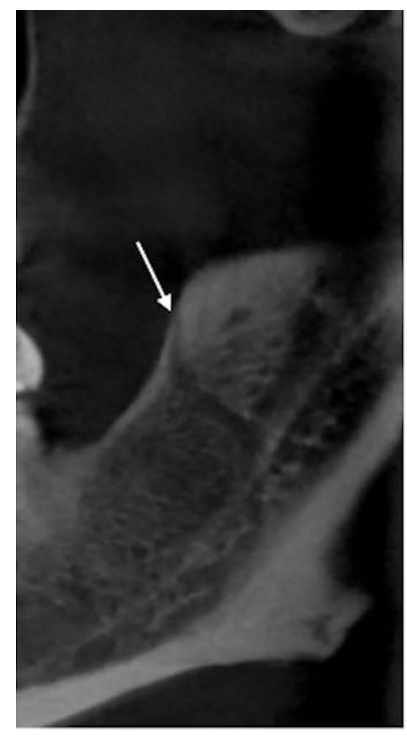

A

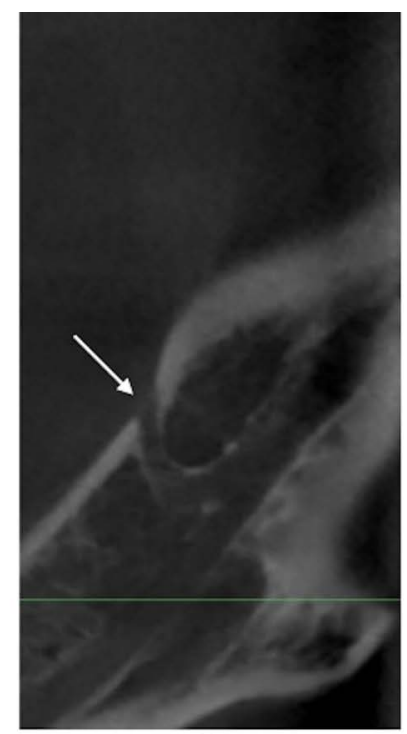

B

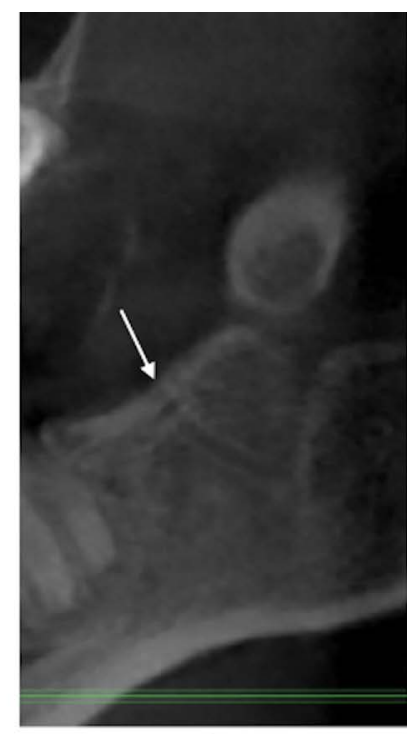

C

Figure 3. A-C. Retromolar canal variations based on cone-beam computed tomography scans (source: Clinical Department of Craniomaxillofacial Surgery, Warsaw, Poland). Classification by von Arx et al. [25].

tance between the branch of the mandibular canal and lateral surface, it means that it is not a result of the measurement technique, but it is a significant characteristic which discriminates both populations.

Among all variables, only the distance between the wall of the mandibular canal and the medial surface of the mandible was statistically significant and correlated with the presence of an additional branch of the mandibular canal. Chances of the additional branch presence were 1.661 times greater for every millimetre of thickness (95\% confidence interval: 1.002-2.755). It means that this measurement, carried out before surgery, may be an indicator of an additional mandibular canal.

\section{DISCUSSION}

There is a great variety of small canal running through the body and ramus of the mandible. Some variations of additional branches of the mandibular canal end behind the molars and hence are called RMC. Some studies report an additional mandibular canal, which originates with a separate foramen on the inner surface of the ramus of the mandible, running anteriorly and laterally to the main mandibular canal and terminating at the retromolar region [11]. This variation is referred to by other authors as the "bifid mandibular canal" $[15,16,20]$ or "retromolar-type canal" [7]. Its incidence cited by the authors is estimated at $0.0-0.06 \%$ and $0.9-66.5 \%[15,16,20]$. Other authors reported varieties when the additional canal originates with a separate foramen as well, but it further runs more anteriorly and inferiorly, with a much more complex pathway. The distal foramen lies on the anterior edge of the coronoid process of the mandible $[13,21]$. This variety is referred to as the 'temporal crest canal' [11, 21] $r$ the 'forward-type canal' [7]. The incidence of extra 'temporal crest canal' is estimated to be $0.3 \%$ [19], $1.7 \%$ [21], $0.45 \%$ [7] or $5.6 \%$ [13]. In the literature, there are reports of rare cases of an additional canal originating in a separate foramen of the mandible and ending at the periodontal ligament space of the third molar [8].

Several classification systems of RMC have been proposed. Han and Hwang [11] divide RMS into three groups: 1) vertical, 2) horizontal, 3) originating in a separate foramen on the medial part of the ramus of the mandible near the mandibular foramen.

Von Arx et al. [25] also distinguish three types of RMC: type A - vertical, type B - slightly curved, type $C$ - horizontal. They distinguished two subtypes of type $A$ and $B$ canals, mainly 1 ) without an additional mandibular canal, and 2) with an additional mandibular canal. Von Arx's classification [25] is the most popular system among researchers, who adopted it in their studies [14].

In our study, most prevalent was type B1 RMC, which was present in 8/10 of contemporary cases. We also found one contemporary case of type $A 1$ and one of type C (Fig. 3). Other authors also concluded that 


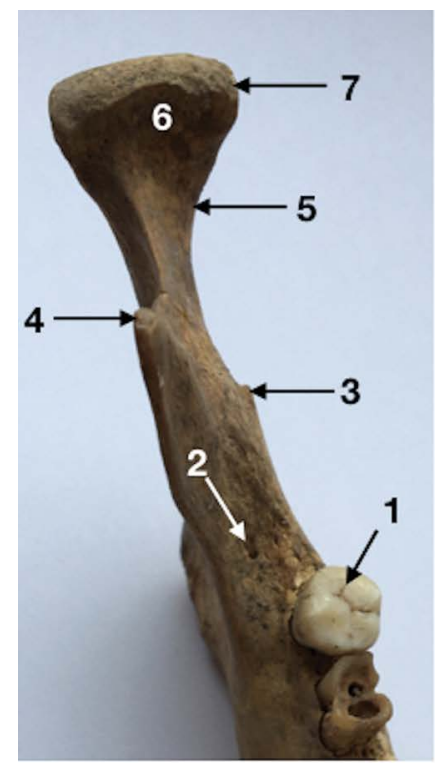

A

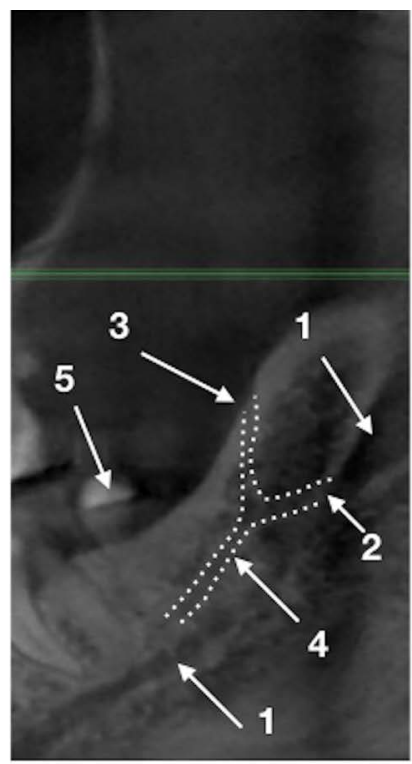

B

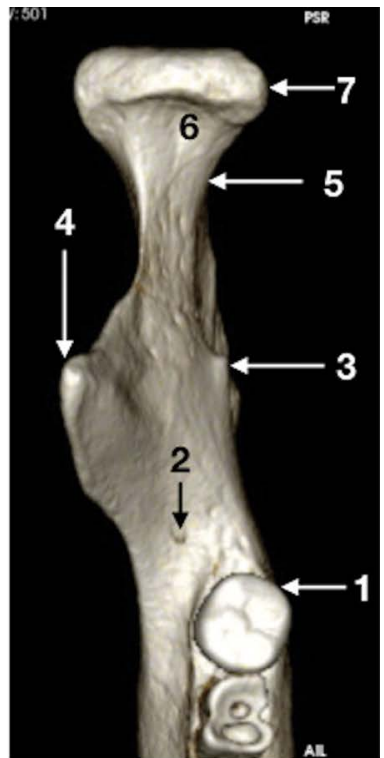

C

Figure 4. Rare variation of retromolar canal (RMC); A. Photography; B. Cone-beam computed tomography (CBCT) scan; C. CBCT-based three-dimensional reconstruction (source: Department of Descriptive and Clinical Anatomy Medical University of Warsaw, Poland); A and C: 1 - third right lower molar; 2 - retromolar foramen (RMF); 3 - lingula; 4 - coronoid process; 5 - neck; 6 - depression of the lateral pterygoid muscle; 7 - head); B: 1 - mandibular canal; 2 - RMC origin; 3 - RMF; 4 - additional mandibular canal; 5 - crown of the third right lower molar in transection).

type B1 is the most common type of RMC found in $66.7 \%$ of cases, compared to type A1 - 26.7\% [14]. Other studies, however, point to type $\mathrm{A} 1$ as the most dominant (41.9\%), followed by B1 - 29\%, A1 $16.1 \%, \mathrm{~B} 2-12.9 \%$ [25].

Furthermore, in the medieval material we found one case of atypical RMC in the shape of a letter $Y$ rotated horizontally (Fig. 4). The RMC consisted of a superior and inferior branch, and an additional mandibular canal originated from the place where both branches merged, but of a much smaller diameter compared to the main canal. This rare variation could be classified as type B2 by Von Arx et al. [25]. Its origin can be explained in terms of mandible development. In the embryonic phase, the mandibular foramen and canal form around the inferior alveolar nerve. The presence of an additional branch of the nerve leads to formation of an extra foramen and canal around that branch, but of a much smaller diameter. Those extra structures are located in the much thinner anterior part of the mandible [17]. Research shows that originally three inferior alveolar nerves are formed, approaching each group of the lower teeth. Later, those nerves fuse together usually forming a single inferior alveolar nerve. Sometimes nerve fusion is stopped, resulting in different anatomical variations of the inferior alveolar nerve branching and thus varying vasculature. They can be appreciated as additional bone canals on CBCT scans $[6,8]$. It is supported by double mandibular canal variations $[7,15,16$, 20] and a rare so-called "trifid mandibular canal" with triple nerves [3].

The incidence of RMF in our study was 10\% (10 per 100 mandible sides) in the contemporary population (based on CBCT scans), and 3.84\% (1 per 26 mandible sides) in the medieval population (macroscopic evaluation). The CBCT scan results are similar to those reported by other authors. The incidence of RMC in other CBCT-based studies was estimated at $4.26 \%$ [11] or $1.66 \%$ [15]. Macroscopic evaluation for RMF in samples brings much higher incidence - 15\% [5] or $37 \%$ [12].

It is worth mentioning that RMF and RMC evaluation on archaeological material has not been conducted so far. The results are in vast discordance with regard to RMF incidence in two subgroups of the archaeological material. We found RMF more often during external visual evaluation of the alveolar portion of the mandible. After later obtaining CBCT scans, it turned out that on the re-evaluation the presence of RMC in the inner bone structure could be confirmed only in single cases. Using McNemar's test, we established that gross evaluation can play a role in 
assessing the presence of mandibular canal branching; however, the specificity is only $68 \%$ with $100 \%$ sensitivity. It means that gross evaluation allows excluding all cases when an additional mandibular canal is absent, however, some cases (about one third) can be false positives. The presence of extra foramens in the retromolar region is not necessarily connected to the presence of additional canals, since the foramens could be a result of damage by long exposure to soil. Many artefacts may be present, caused by the bones resting in unfavourable environment for a long time.

In studies by other authors, RMC was observed in $13 / 50$ patients ( $26 \%$ ), with confirmed double RMC [14] in 3.4\% [10] and $23 \%$ [23] of cases, respectively.

The RMF diameter on CBCT scans was $0.5 \mathrm{~mm}$ (in the medieval material), and $0.7-2.0 \mathrm{~mm}$ (in the contemporary material). Those results are similar to those reported by other authors. According to Kikuta et al. [14], the RMF diameter ranges from 0.6 to $2.3 \mathrm{~mm}$. Smaller values in the medieval material could be a result of post mortem bone decay.

The mandibular canal diameter reported in the literature is estimated at $2 \mathrm{~mm}$ bilaterally [1]. In the contemporary material, we established that the mandibular canal diameter in the coronal section was $2.98 \mathrm{~mm}$ (ranging $1.7-4.6 \mathrm{~mm}$ ). In the medieval material, it was $2.66 \mathrm{~mm}(1.9-3.9 \mathrm{~mm})$.

Mean distance from the RMF to the medial surface of the alveolar part of the mandible on CBCT scans in the contemporary material was $0.338 \mathrm{~mm}$ (ranging from 1.6 to 7.7 ). In the archaeological material, the distance was $3.5 \mathrm{~mm}$.

Mean distance from the RMF to the lateral surface of the alveolar part of the mandible on CBCT scans in the contemporary material was $0.586 \mathrm{~mm}$ (ranging from 3.6 to 9.8).

Mean distance from the RMF to the distal surface of the third molar was $4.7 \mathrm{~mm}$, and to the distal surface of the second molar was $12.13 \mathrm{~mm}$. Other authors in their study on 46 mandibles reported RMF in $52 \%(24 / 46)$ and retromolar location in $37 \%$ (34/90). On the mandibles with dentition, the foramen was present in $48 \%(12 / 26)$ or in 14 out of 90 sides (33\%). In relation to the second molar, the mean distance was $14.4 \mathrm{~mm}$ (8.1-21.6). In relation to the first molar, it was $23.0 \mathrm{~mm}$ (18.3-27.6) [12]. Bilencenogly and Tuncer [5] reported that the mean distance from the RMF to the second molar was $11.9 \mathrm{~mm}$, while to the third molar it was $4.23 \mathrm{~mm}$. From the clinician's point of view, those are extremely important statistical data, showing how close to the tooth's surface the RMF can be located. During surgical removal of fully or partially impacted wisdom teeth, it is necessary to dissect bone in the distal part of the retromolar region. At this point, RMC is most likely to be injured.

In the literature, there are reports suggesting that performing surgery with a triangular flap design allows the risk of postoperative complications to be reduced [9]. However, not only soft tissues should be considered, but also bone structures of the alveolar part of the mandible. Particularly, retromolar bone dissection should be limited, and bone removal at the base of the coronoid process of the mandible should be avoided, especially when CBCT cannot be obtained beforehand.

Mean distance from the mandibular canal to the medial surface of the alveolar part of the mandible in the coronal section on CBCT scan in the contemporary material was $2.838 \mathrm{~mm}$ (ranging from 0.5 to 8.7 ). In the archaeological material, it was $3.06 \mathrm{~mm}(0.8-5.8)$. Mean distance from the mandibular canal to the lateral surface of the alveolar part of the mandible in the contemporary material was $4.14 \mathrm{~mm}$ (1.9-8.4). In the medieval material, it was $3.5(1.3-7.2)$. Studies by other authors gave similar results, confirming that the distance from the mandibular canal to the lateral surface of the alveolar part of the mandible is longer than to the medial surface $(9.89 \pm 0.81$ vs. $6.37 \pm 0.79 \mathrm{~mm}$ ) [24]. Based on the statistical analysis, we established that the distance from the mandibular canal to the medial surface of the body of the mandible is a predictor of RMC presence. This observation can be used for intraoperative evaluation to avoid iatrogenic injury to the retromolar branch of the inferior alveolar artery.

\section{CONCLUSIONS}

In our study, we found a statistically significant positive correlation between the RMC incidence and the thickness of bone medially to the mandibular canal. The likelihood of an additional mandibular canal was 1.661 greater for each millimetre of bone thickness.

In the contemporary material, we observed a significantly wider diameter of the mandibular canal in the coronal section, together with a significantly larger height in the sagittal section, and significantly larger distance from the mandibular canal wall to the medial surface of the mandible in the archaeological material. However, the distance from the RMC to 
the lateral surface of the mandible was significantly higher in the archaeological material than in the contemporary samples.

Identification of RMF in the archaeological material based on gross evaluation may be falsely negative due to possible formation of extra foramens on the surface of the bone due to damage caused by the bone resting in soil. Therefore, CBCT scan is the most precise tool used to identify retromolar foramen and retromolar canal.

\section{REFERENCES}

1. Agbaje JO, de Casteele EV, Salem AS, et al. Tracking of the inferior alveolar nerve: its implication in surgical planning. Clin Oral Investig. 2017; 21(7): 2213-2220, doi: 10.1007/ s00784-016-2014-x, indexd in Pubmed: 27878463.

2. Ascadi G, Nemeskeri J. History of human life span and mortality. Budapest. 1970, doi: org/10.1002/ajpa.1330360219.

3. Auluck A, Pai KM. Trifid mandibular nerve canal. Dentomaxillofac Radiol. 2005; 34(4): 259, doi: 10.1259/ dmfr/57994569, indexed in Pubmed: 15961604.

4. Bass WM. Human Osteology a Laboratory and Field Manual. souri Archeological Society 1995.

5. Bilecenoglu B, Tuncer N. Clinical and anatomical study of retromolar foramen and canal. J Oral Maxillofac Surg. 2006; 64(10): 1493-1497, doi: 10.1016/j. joms.2006.05.043, indexed in Pubmed: 16982307.

6. Chávez-Lomeli ME, Mansilla Lory J, Pompa JA, et al. The human mandibular canal arises from three separate canals innervating different tooth groups. J Dent Res. 1996; 75(8): 1540-1544, doi: 10.1177/00220345960750080401, indexed in Pubmed: 8906121.

7. Choi YY, Han SS. Double mandibular foramen leading to the accessory canal on the mandibular ramus. Surg Radiol Anat. 2014 ; 36(9): 851-855, doi: 10.1007/s00276-0141310-x, indexed in Pubmed: 24817561.

8. Das S, Suri RK. An anatomico-radiological study of an accessory mandibular foramen on the medial mandibular surface. Folia Morphol. 2004; 63(4): 511-513, indexed in Pubmed: 15712153.

9. Guy S. Flap design affects recovery from wisdom tooth surgery. Int J Oral Maxillofac Surg. 2012; 41: 1020-1024.

10. Fiuza Leite GM, Pelinsar iLana J, de Carvalho Machado V, et al. Anatomic variations and lesions of the mandibular canal detected by cone beam computed tomography. Surg Radiol Anat. 2014; 36(8): 795-804, doi: 10.1007/s00276013-1247-5, indexed in Pubmed: 24337387.

11. Han SS, Hwang YS. Cone beam CT findings of retromolar canals in a Korean population. Surg Radiol Anat. 2014; 36(9): 871-876, doi: 10.1007/s00276-014-1262-1, indexed in Pubmed: 24504621.

12. Kawai T, Asaumi R, Sato I, et al. Observation of the retromolar foramen and canal of the mandible: a CBCT and macroscopic study. Oral Radiology. 2011; 28(1): 10-14, doi: 10.1007/s11282-011-0074-9.
13. Kawai T, Asaumi R, Kumazawa Y, et al. Observation of the temporal crest canal in the mandibular ramus by cone beam computed tomography and macroscopic study. Int J Comput Assist Radiol Surg. 2014; 9(2): 295-299, doi: 10.1007/s11548-013-0931-6, indexed in Pubmed: 23934198.

14. Kikuta S, Iwanaga J, Nakamura K, et al. The retromolar canals and foramina: radiographic observation and application to oral surgery. Surg Radiol Anat. 2018; 40(6): 647-652, doi: 10.1007/s00276-018-2005-5, indexed in Pubmed: 29594335.

15. Kuribayashi A, Watanabe $H$, Imaizumi A, et al. Bifid mandibular canals: cone beam computed tomography evaluation. Dentomaxillofac Radiol. 2010; 39(4): 235-239, doi: 10.1259/dmfr/66254780, indexed in Pubmed: 20395465.

16. Langlais RP, Broadus R, Glass BJ. Bifid mandibular canals in panoramic radiographs. J Am Dent Assoc. 1985; 110(6): 923-926, doi: 10.14219/jada.archive.1985.0033, indexed in Pubmed: 3860553.

17. Manikandhan R, Mathew PC, Naveenkumar J, et al. A rare variation in the course of the inferior alveolar nerve. Int J Oral Maxillofac Surg. 2010; 39(2): 185-187, doi: 10.1016/j.ijom.2009.12.007, indexed in Pubmed: 20083390.

18. Martin R, Saller K. Lerhbuch der Anthropologie in Systematicher Darstellung. Stutgard 1957.

19. Narayana K, Prashanthi N. Incidence of large access- roy mandibular foramen in human mandibles. Eur J Anat. 2003; 7(3): 139-141.

20. Nortjé CJ, Farman AG, Grotepass FW. Variations in the normal anatomy of the inferior dental (mandibular) canal: a retrospective study of panoramic radiographs from 3612 routine dental patients. Br J Oral Surg. 1977; 15(1): 55-63, doi: 10.1016/0007-117x(77)90008-7, indexed in Pubmed: 268217.

21. Ossenberg NS. Temporal crest canal: case report and statistics on a rare mandibular variant. Oral Surg Oral Med Oral Pathol. 1986; 62(1): 10-12, doi: 10.1016/00304220(86)90062-9, indexed in Pubmed: 3523363.

22. Patil S, Matsuda Y, Nakajima K, et al. Retromolar canals as observed on cone-beam computed tomography: their incidence, course, and characteristics. Oral Surg Oral Med Oral Pathol Oral Radiol. 2013; 115(5): 692-699, doi: 10.1016/j. oooo.2013.02.012, indexed in Pubmed: 23601225.

23. Poirot $G$, Delattre JF, Palot $C$, et al. The inferior alveolar artery in its bony course. Surg Radiol Anat. 1986; 8(4): 237-244, doi: 10.1007/BF02425073, indexed in Pubmed: 3107147.

24. Sun-Kyoung Yu, Myoung-Hwa L, Yong Hyun J, et al. Anatomical configuration of the inferior alveolar neurovascular bundle: a histomorphometric analysis. Surg Radiol Anat. 2016; 38(2): 195-201, doi: 10.1007/s00276-0151540-6, indexed in Pubmed: 26272703.

25. von Arx T, Hänni A, Sendi P, et al. Radiographic study of the mandibular retromolar canal: an anatomic structure with clinical importance. J Endod. 2011; 37(12): 1630-1635, doi: 10.1016/j.joen.2011.09.007, indexed in Pubmed: 22099895. 